MINOTAUR 



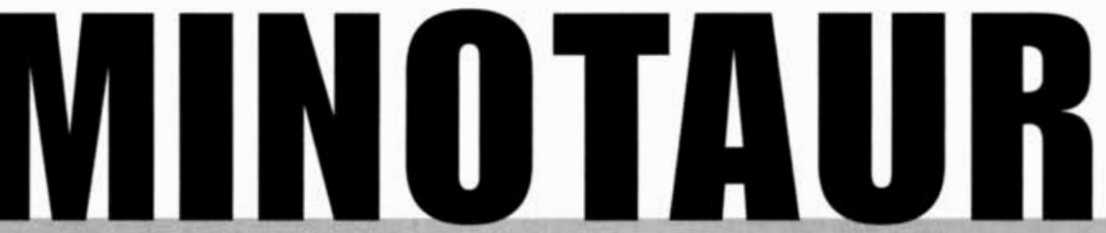

French Military Justice and the Aernoult-Rousset Affair

\section{John Gerullo}

\section{min}

NORTHERN ILLINOIS UNIVERSITY PRESS 
(C) 2011 by Northern Illinois University Press

Published by the Northern Illinois University Press, DeKalb, Illinois 60115

All Rights Reserved

Design by Shaun Allshouse

Library of Congress Cataloging-in-Publication Data

Cerullo, John J., 1949

Minotaur : French military justice and the Aernoult-Rousset affair / John Cerullo. p. $\mathrm{cm}$.

Includes bibliographical references and index.

ISBN 978-0-87580-433-0 (clothbound : alk. paper)

1. Courts-martial and courts of inquiry-France-History-20th century. I. Title.

KJV7568.C47 2010

343.44 '0143-dc22

2010019102 
TO SHAWN Simply the best 


$$
\text { , }
$$

